\title{
ERRATUM
}

Hamza Özer · Şükrü Solak · Sacit Turanli

Gül Baltaci · Tuğrul Çolakoğlu • Selcuk Bolukbasí

\section{Intercondylar fractures of the distal humerus treated with the triceps-reflecting anconeus pedicle approach}

\section{Arch Orthop Trauma Surg (2005) 125:469-474. DOI 10.007/s00402-005-0026-0}

The figures appeared in the wrong order. Figure 1 with its legend should be Fig. 3 and vice versa.
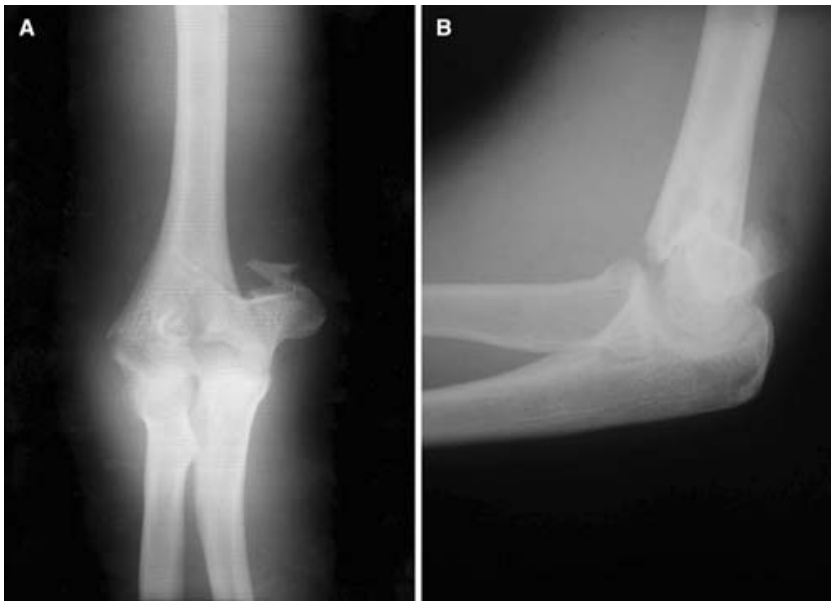

Fig. 1 A Type C2 intercondylar humerus fracture after a fall on the elbow in a 17-year-old patient (Case no 6). a Anteroposterior view, b lateral view
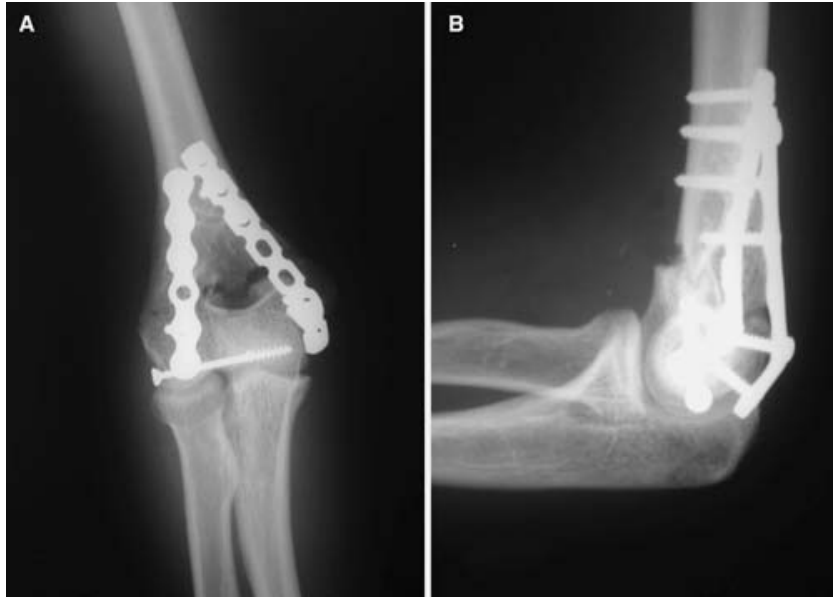

The online version of the original article can be found at http://dx.doi.org/10.007/s00402-005-0026-0

H. Özer $(\bowtie) \cdot S$. Turanli $\cdot$ S. Bolukbasí

Department of Orthopaedics and Traumatology,

University of Gazi, Bardacik S. 63/21, K.Esat, 06660 Ankara, Turkey

E-mail: heozer@superonline.com

Tel: + 90-532-3323179

Fax: $+90-312-2129008$

Ş. Solak $\cdot$ T. Çolakoğlu

Department of Orthopaedics and Traumatology,

Emergency Care and Traumatology Hospital,

Ankara, Turkey

G. Baltaci

School of Physiotherapy and Rehabilitation,

University of Hacettepe, Ankara, Turkey

Fig. 3 Postoperative X-rays of the same patient. a Anteroposterior view, b lateral view 